\title{
Fatty acid synthase gene expression in human adipose tissue: association with obesity and type 2 diabetes
}

\author{
J. Berndt $\cdot$ P. Kovacs $\cdot$ K. Ruschke $\cdot$ N. Klöting $\cdot$ \\ M. Fasshauer • M. R. Schön • A. Körner • M. Stumvoll • \\ M. Blüher
}

Received: 7 March 2007 / Accepted: 28 March 2007 / Published online: 11 May 2007

(C) Springer-Verlag 2007

\begin{abstract}
Aims/hypothesis Increased expression and activity of the lipogenic pathways in adipose tissue may contribute to the development of obesity. As a central enzyme in lipogenesis, the gene encoding fatty acid synthase (FASN) was identified as a candidate gene for determining body fat. In the present study we tested the hypothesis that increased FASN expression links metabolic alterations of excess energy intake, including hyperinsulinaemia, dyslipidaemia and altered adipokine profile to increased body fat mass.

Subjects and methods In paired samples of visceral and subcutaneous adipose tissue from 196 participants (lean or obese), we investigated whether FASN mRNA expression (assessed by PCR) in adipose tissue is increased in obesity and related to visceral fat accumulation, measures of insulin sensitivity (euglycaemic-hyperinsulinaemic clamp) and glucose metabolism.
\end{abstract}

J. Berndt $\cdot$ P. Kovacs $\cdot$ K. Ruschke $\cdot$ N. Klöting $\cdot$ M. Fasshauer $\cdot$

M. Stumvoll $\cdot$ M. Blüher $(\square)$

Department of Internal Medicine III, University of Leipzig,

Ph.-Rosenthal-Str. 27,

04103 Leipzig, Germany

e-mail: bluma@medizin.uni-leipzig.de

J. Berndt $\cdot$ P. Kovacs

Junior Research Group N06, Interdisciplinary Center of Clinical

Research Leipzig, Faculty of Medicine, University of Leipzig,

Leipzig, Germany

\section{R. Schön}

Department of Surgery II, University of Leipzig,

Leipzig, Germany

\section{A. Körner}

University Hospital for Children and Adolescents,

University of Leipzig,

Leipzig, Germany
Results FASN mRNA expression was increased by 1.7 -fold in visceral vs subcutaneous fat. Visceral adipose tissue FASN expression was correlated with FASN protein levels, subcutaneous $F A S N$ expression, visceral fat area, fasting plasma insulin, serum concentrations of IL-6, leptin and retinol-binding protein 4 (RBP4), and inversely with measures of insulin sensitivity, independently of age, sex and BMI. Moreover, we found significant correlations between FASN expression and markers of renal function, including serum creatinine and urinary albumin excretion. Conclusions/interpretation Increased FASN gene expression in adipose tissue is linked to visceral fat accumulation, impaired insulin sensitivity, increased circulating fasting insulin, IL-6, leptin and RBP4, suggesting an important role of lipogenic pathways in the causal relationship between consequences of excess energy intake and the development of obesity and type 2 diabetes.

Keywords Fatty acid synthase $\cdot$ Obesity Type 2 diabetes

$\begin{array}{ll}\text { Abbreviations } \\ \text { CoA } & \text { coenzyme A } \\ \text { CT } & \text { computed tomography } \\ \text { FASN } & \text { fatty acid synthase } \\ \text { RBP4 } & \text { retinol-binding protein } 4\end{array}$

\section{Introduction}

Fatty acid synthase (FASN) may play a role in the regulation of body weight and the development of obesity [1-4]. The body weight gain of normal subjects fed an excess energy intake (approximately 2.5 times energy expenditure, with the excess derived from carbohydrate) 
cannot be explained by the increase in liver lipogenesis, suggesting that significant de novo lipogenesis occurs in other tissues, most likely adipose tissue [5]. However, although the key enzymes of fatty acid synthesis are present in human adipose tissue, their contribution to whole-body lipogenesis is considered to be lower than that of the liver $[6,7]$. Feeding simple carbohydrates also substantially increases the activity of FASN [8], which is necessary for de novo synthesis of long-chain, saturated fatty acids from acetyl coenzyme A (CoA), malonyl CoA and NADPH [9]. Expression of the FASN gene and FASN activity are increased by insulin in cultured human adipocytes, suggesting that insulin sensitivity plays a role in their regulation [10]. Moreover, higher levels of FASN mRNA and FASN protein production were shown in insulin-resistant large adipocytes compared with small adipocytes in wild-type mice $[11,12]$.

Recent studies have reported that inhibition of FASN in rodents induces profound weight loss and reduced food intake, suggesting that FASN may be involved in obesity through regulation of feeding behaviour and energy homeostasis $[1,2,13,14]$. The FASN inhibitor C75 acts both centrally to reduce food intake and peripherally to increase fatty acid oxidation [1, 14], leading to reduced fat mass and resolution of fatty liver in mice [2] and chickens [15] with diet-induced obesity. Whether these effects also play a role in human obesity needs to be clarified, especially since adipose tissue lipogenic capacity and FASN expression have been shown to be lower in humans than in rodents [6]. In turkeys, FASN gene polymorphisms are associated with increased fat mass [16]. Furthermore, in genetic studies, a novel missense mutation in the human FASN gene resulting in a Val>Ile substitution at codon 1483 was shown to be associated with lower percentage body fat and BMI in Pima Indians [3] and in German children [17]. In humans, FASN protein is produced at high levels in liver, lung and intra-abdominal adipose tissue [18]. Taken together, these studies demonstrate that $F A S N$ is a candidate gene for the pathophysiology of human obesity and its related metabolic alterations.

We therefore tested the hypothesis that increased FASN activity and FASN expression is a mediator that links the metabolic consequences of caloric excess, including insulin resistance, dyslipidaemia and altered adipokine serum profile, to increased body fat mass. Thereby, our aim was to dissect the most significant correlates of altered FASN expression in obesity and type 2 diabetes. We studied FASN mRNA expression in adipose tissue using quantitative realtime RT-PCR in paired samples of visceral and subcutaneous adipose tissue from 196 volunteers who varied widely in terms of obesity, body fat distribution, insulin sensitivity and glucose tolerance.

\section{Subjects and methods}

Paired samples of visceral and subcutaneous adipose tissue were obtained from 196 men $(n=98)$ and women $(n=98)$ who underwent open abdominal surgery for gastric banding, cholecystectomy, appendectomy, weight reduction surgery, abdominal injuries or explorative laparotomy. The subjects' age ranged from 24 to 86 years and BMI ranged from 20.8 to $54.1 \mathrm{~kg} / \mathrm{m}^{2}$. Using an OGTT, we identified 67 individuals with either type 2 diabetes $(n=36)$ or IGT $(n=$ 31). All subjects had a stable weight, defined as the absence of fluctuations of $>2 \%$ of body weight for at least 3 months before surgery. Patients with malignant diseases or any acute or chronic inflammatory disease, as determined by a leucocyte count of $>7,000 \mathrm{Gpt} / 1$, C-reactive protein levels of $>50 \mathrm{mg} / 1$ or clinical signs of infection, were excluded from the study. After explantation, samples of visceral and subcutaneous adipose tissue were immediately frozen in liquid nitrogen. The study was approved by the ethics committee of the University of Leipzig. All participants gave written informed consent before taking part in the study.

Assays and measures of glucose metabolism Basal blood samples were taken after an overnight fast. Plasma insulin was measured with an enzyme immunometric assay for the IMMULITE automated analyser (Diagnostic Products, Los Angeles, CA). Plasma adiponectin and leptin levels were assessed by RIA (Linco Research, St Charles, MO). Serum IL-6 levels were measured using an ELISA (Quantikine IL-6; R\&D Systems, Oxford, UK). RBP4 (retinol-binding protein 4) was measured as previously described [19]. Patients consumed a high-carbohydrate diet for the 3 days prior to the OGTT. Following an overnight fast, the OGTT was performed using $75 \mathrm{~g}$ of standardised glucose solution (Glucodex solution $75 \mathrm{~g}$; Merieux, Montreal, QC, Canada). Venous blood samples were taken at 0,60 and $120 \mathrm{~min}$ for measurement of plasma glucose concentrations. Insulin sensitivity was assessed using the euglycaemichyperinsulinaemic clamp method [20]. A cut-off value for insulin resistance was arbitrarily chosen from the euglycaemic-hyperinsulinaemic clamp results of more than 120 individuals with the same population background and underwent the clamp under the same conditions as previously reported [21].

Measures of body fat content BMI was calculated as weight (in $\mathrm{kg}$ ) divided by the square of height (in $\mathrm{m}$ ). Waist and hip circumferences were measured, and the WHR was calculated. Percentage body fat was measured by dual-energy X-ray absorptiometry (DEXA). In addition, abdominal visceral and subcutaneous fat areas were 
calculated using computed tomography $(\mathrm{CT})$ scans at the level of L4-L5.

Analysis of human FASN mRNA and FASN levels Human FASN gene expression was measured by quantitative realtime RT-PCR in a fluorescent temperature cycler using the TaqMan assay, and fluorescence was detected on an ABI PRISM 7000 sequence detector (Applied Biosystems, Darmstadt, Germany). Total RNA was isolated from paired subcutaneous and visceral adipose tissue samples using TRIzol (Life Technologies, Grand Island, NY), and $1 \mu \mathrm{g}$ RNA was reverse transcribed with standard reagents (Life Technologies). From each RT-PCR sample, $2 \mu 1$ was amplified in a 26- $\mu$ l PCR using the Brilliant SYBR Green QPCR Core Reagent Kit from Stratagene (La Jolla, CA) according to the manufacturer's instructions. Samples were incubated in the ABI PRISM 7000 sequence detector for an initial denaturation at $95^{\circ} \mathrm{C}$ for $10 \mathrm{~min}$, followed by $40 \mathrm{PCR}$ cycles of $95^{\circ} \mathrm{C}$ for $15 \mathrm{~s}, 60^{\circ} \mathrm{C}$ for $1 \mathrm{~min}$ and $72^{\circ} \mathrm{C}$ for $1 \mathrm{~min}$. The following primers were used: human $F A S N$ (accession no. NM 004104) 5'-CGCGTGGCCGGCTACTCCTAC-3' (sense) and 5'-CGGCTGCCACACGCTCCTCT-3' (antisense). SYBR Green I fluorescence emissions were monitored after each cycle. Human FASN mRNA expression was calculated relative to the expression of $18 \mathrm{~S}$ rRNA, determined by a premixed assay on demand for human $18 \mathrm{~S}$ rRNA (PE Biosystems). Amplification of specific transcripts was confirmed by melting curve profiles (cooling the sample to $68^{\circ} \mathrm{C}$ and heating slowly to $95^{\circ} \mathrm{C}$ with measurement of fluorescence) at the end of each PCR. The specificity of the PCR was further verified by subjecting the amplification products to agarose gel electrophoresis. FASN protein expression (visceral and subcutaneous) was measured in a representative subgroup of lean $(n=10)$, visceral $(n=10)$, and subcutaneous obese $(n=10)$ subjects by western blot analysis using a human FASN-specific primary antibody (H-300; Santa Cruz, Heidelberg, Germany). Three blots of the samples were scanned using a Molecular Dynamics Storm PhosphoImager and quantified with ImageQuant software.

Statistical analyses Data are shown as means \pm SEM unless stated otherwise. Before statistical analysis, non-normally distributed parameters were logarithmically transformed to approximate a normal distribution. Differences in expression between visceral and subcutaneous adipose tissue were assessed using the paired Student's $t$ test, and differences between more than two groups were analysed by the Bonferroni-Holm test. Linear relationships were assessed by least-square regression analysis. Multivariate linear relation-

Table 1 Anthropometric and metabolic characteristics of the study groups

\begin{tabular}{|c|c|c|c|c|c|c|}
\hline & \multicolumn{2}{|l|}{ Lean } & \multicolumn{2}{|c|}{ Predominantly viscerally obese } & \multicolumn{2}{|c|}{ Predominantly subcutaneously obese } \\
\hline & NGT & IGT/T2D & NGT & IGT/T2D & NGT & IGT/T2D \\
\hline Men/women & $28 / 25$ & $5 / 8$ & $9 / 12$ & $10 / 11$ & $29 / 26$ & $17 / 16$ \\
\hline Age (years) & $48.8 \pm 2.37$ & $39.0 \pm 3.2^{\mathrm{a}}$ & $61.2 \pm 2.6^{\mathrm{b}}$ & $61.4 \pm 3.7^{\mathrm{b}}$ & $57.8 \pm 2.2^{\mathrm{b}}$ & $53.6 \pm 3.2^{\mathrm{b}, \mathrm{c}}$ \\
\hline BMI $\left(\mathrm{kg} / \mathrm{cm}^{2}\right)$ & $24.0 \pm 0.15$ & $24.6 \pm 0.2$ & $32.3 \pm 1.27^{\mathrm{b}}$ & $34.0 \pm 1.55^{\mathrm{b}}$ & $34.7 \pm 0.9^{b}$ & $34.4 \pm 1.8^{\mathrm{b}}$ \\
\hline WHR & $0.85 \pm 0.02$ & $0.88 \pm 0.02$ & $1.12 \pm 0.02^{\mathrm{b}}$ & $1.11 \pm 0.03^{\mathrm{b}}$ & $1.0 \pm 0.02^{\mathrm{b}}$ & $1.1 \pm 0.05^{\mathrm{b}}$ \\
\hline Body fat $(\%)$ & $21.6 \pm 0.36$ & $27 \pm 0.5^{\mathrm{a}}$ & $31.8 \pm 1.15^{\mathrm{b}}$ & $33.4 \pm 2.0^{\mathrm{b}}$ & $38.7 \pm 1.4^{\mathrm{b}, \mathrm{c}}$ & $39.5 \pm 2.9^{\mathrm{b}, \mathrm{c}}$ \\
\hline Visceral fat area $\left(\mathrm{cm}^{2}\right)$ & $45.7 \pm 2.12$ & $78 \pm 1.9^{\mathrm{a}}$ & $292.7 \pm 12.3^{\mathrm{b}}$ & $296.4 \pm 16.9^{\mathrm{b}}$ & $157.4 \pm 8.4^{\mathrm{b}, \mathrm{c}}$ & $175.0 \pm 12.8^{\mathrm{a}, \mathrm{b}, \mathrm{c}}$ \\
\hline $\mathrm{SC}$ fat area $\left(\mathrm{cm}^{2}\right)$ & $56.1 \pm 2.66$ & $56 \pm 2.9$ & $404 \pm 28.7^{\mathrm{b}}$ & $428 \pm 57^{\mathrm{b}}$ & $805.7 \pm 87.9^{\mathrm{b}, \mathrm{c}}$ & $950.1 \pm 57.8^{\mathrm{a}, \mathrm{b}, \mathrm{c}}$ \\
\hline $\mathrm{HbA}_{1 \mathrm{c}}(\%)$ & $5.3 \pm 0.03$ & $6.3 \pm 0.05^{\mathrm{a}}$ & $5.66 \pm 0.06^{\mathrm{b}}$ & $6.2 \pm 0.1^{\mathrm{a}, \mathrm{b}}$ & $5.5 \pm 0.04$ & $6.1 \pm 0.1^{\mathrm{a}}$ \\
\hline Fasting blood glucose (mmol/l) & $5.3 \pm 0.05$ & $7.8 \pm 0.2^{\mathrm{a}}$ & $5.3 \pm 0.10$ & $6.2 \pm 0.2^{\mathrm{a}, \mathrm{b}}$ & $5.3 \pm 0.08$ & $6.4 \pm 0.2^{\mathrm{a}, \mathrm{b}}$ \\
\hline Fasting plasma insulin (pmol/l) & $30.1 \pm 1.77$ & $125 \pm 24^{\mathrm{a}}$ & $125.3 \pm 16.8^{\mathrm{b}}$ & $262.3 \pm 23.9^{\mathrm{a}, \mathrm{b}}$ & $112.0 \pm 9.0^{\mathrm{b}}$ & $282.0 \pm 46.4^{\mathrm{a}, \mathrm{b}}$ \\
\hline 2 h OGTT glucose $(\mathrm{mmol} / \mathrm{l})$ & $5.9 \pm 0.1$ & $13.5 \pm 2.9^{\mathrm{a}}$ & $6.3 \pm 0.20^{\mathrm{b}}$ & $12.0 \pm 1.1^{\mathrm{a}}$ & $6.0 \pm 0.1$ & $11.6 \pm 1.0^{\mathrm{a}}$ \\
\hline Glucose infusion rate $\left(\mathrm{mg} \mathrm{kg}^{-1} \mathrm{~min}^{-1}\right)$ & $96.0 \pm 1.23$ & $59.0 \pm 5.9^{\mathrm{a}}$ & $48.0 \pm 6.6^{\mathrm{b}}$ & $26.3 \pm 4.9^{\mathrm{a}, \mathrm{b}}$ & $65.2 \pm 4.1^{\mathrm{b}, \mathrm{c}}$ & $49.3 \pm 9.9^{\mathrm{a}, \mathrm{c}}$ \\
\hline NEFA $(\mathrm{mmol} / \mathrm{l})$ & $0.3 \pm 0.02$ & $0.6 \pm 0.01^{\mathrm{a}}$ & $0.7 \pm 0.06^{\mathrm{b}}$ & $0.8 \pm 0.08$ & $0.5 \pm 0.04^{\mathrm{b}, \mathrm{c}}$ & $0.6 \pm 0.1^{\mathrm{c}}$ \\
\hline Total cholesterol (mmol/l) & $5.3 \pm 0.13$ & $5.3 \pm 0.11$ & $5.6 \pm 0.2^{\mathrm{b}}$ & $6.0 \pm 0.2^{\mathrm{a}, \mathrm{b}}$ & $5.0 \pm 0.1$ & $5.5 \pm 0.2^{\mathrm{a}, \mathrm{c}}$ \\
\hline HDL-cholesterol (mmol/l) & $1.6 \pm 0.08$ & $1.1 \pm 0.09^{\mathrm{a}}$ & $1.3 \pm 0.05^{\mathrm{b}}$ & $1.41 \pm 0.08^{\mathrm{a}, \mathrm{b}}$ & $1.4 \pm 0.05^{\mathrm{b}}$ & $1.5 \pm 0.1^{\mathrm{b}}$ \\
\hline LDL-cholesterol (mmol/l) & $2.9 \pm 0.11$ & $3.0 \pm 0.2$ & $3.3 \pm 0.1^{\mathrm{b}}$ & $3.6 \pm 0.2^{\mathrm{b}}$ & $2.6 \pm 0.08^{\mathrm{c}}$ & $3.2 \pm 0.2^{\mathrm{a}, \mathrm{c}}$ \\
\hline \multicolumn{7}{|l|}{ Leptin $(\mathrm{pmol} / \mathrm{l})$} \\
\hline Men & $3.3 \pm 0.80$ & $3.8 \pm 0.3$ & $22.9 \pm 2.9^{\mathrm{b}}$ & $20.4 \pm 4.6^{\mathrm{b}}$ & $21.5 \pm 1.9^{\mathrm{b}}$ & $14.3 \pm 2.4^{\mathrm{a}, \mathrm{b}, \mathrm{c}}$ \\
\hline Women & $8.4 \pm 1.0$ & $9.2 \pm 0.5$ & $32.3 \pm 3.7^{\mathrm{b}}$ & $38.6 \pm 6.0^{\mathrm{b}}$ & $28.0 \pm 2.2^{\mathrm{b}}$ & $32.3 \pm 3.2^{\mathrm{b}}$ \\
\hline
\end{tabular}

Data are means \pm SEM

${ }^{\mathrm{a}} p<0.05$ for IGT/T2D vs NGT within the same study group; ${ }^{\mathrm{b}} p<0.05$ for visceral or subcutaneous obese vs lean; ${ }^{\mathrm{c}} p<0.05$ for visceral obese vs subcutaneous obese

$S C$ subcutaneous, $T 2 D$ type 2 diabetes 
Fig. 1 FASN mRNA expression in visceral and subcutaneous adipose tissue in lean, obese, NGT, IGT and type 2 diabetic subjects. FASN mRNA levels in the entire study population ( $n=$ 196) (a), male $(n=98)$ and female $(n=98)$ participants $(\mathbf{b})$, subgroups of lean $(n=53)$, visceral obese (vis, $n=21)$ and subcutaneous obese (SC, $n=55$ ) participants with NGT (c), subgroups of participants with NGT $(n=129)$ or IGT or type 2 diabetes (IGT/T2D, $n=67)$ (d).

Visceral and subcutaneous fat areas were calculated using CT scans at the level of L4-L5. e FASN protein levels were measured in homogenates of visceral adipose tissue from lean $(n=10)$, visceral $(n=10)$, and subcutaneous obese $(n=10)$ participants.

For each group, a representative western blot and quantitation of the data from three independent experiments are shown. f Correlation between $F A S N$ mRNA expression and FASN protein levels in visceral adipose tissue $\left(R^{2}=0.5, p<0.001\right)$. Values are means \pm SEM. $* p<0.01$ for comparisons of fat depot-specific levels within the groups; ${ }^{\#} p<$ 0.01 for differences between the obesity groups and lean subjects; ${ }^{+} p<0.05$ for differences between T2D and NGT
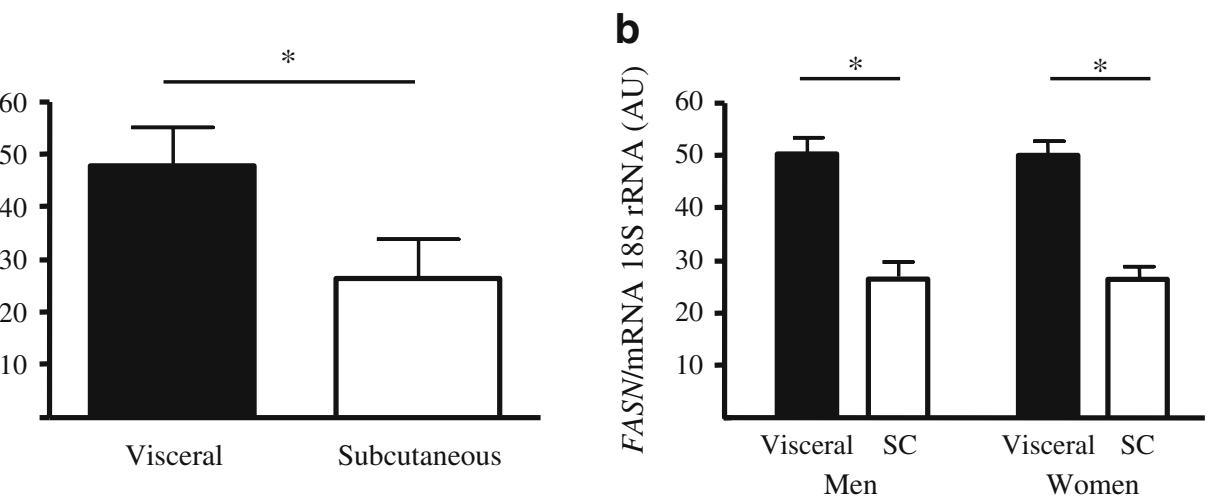

c

d

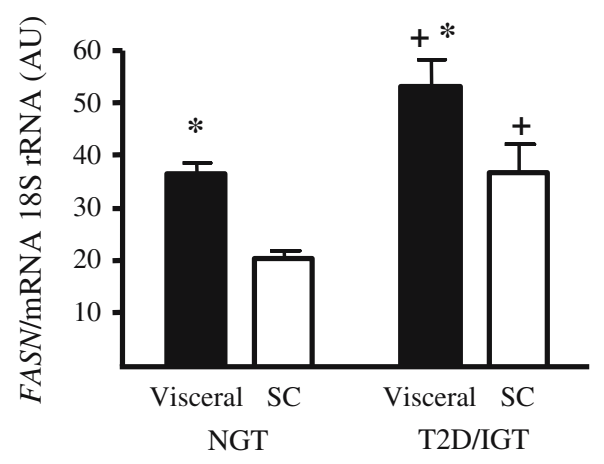

f

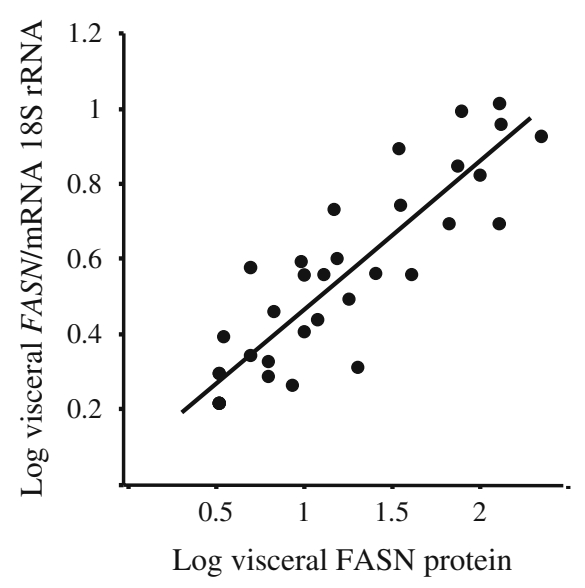

ships were assessed by a general linear model. Statistical software from the SAS Institute (Cary, NC) was used. A $p$ value of $<0.05$ was considered to be statistically significant.

\section{Results}

Visceral and subcutaneous FASN $m R N A$ and FASN levels The anthropometric and metabolic characteristics of the volunteers are summarised in Table 1. Analysis of 198 paired samples of visceral and subcutaneous adipose tissue revealed that FASN mRNA expression was $\sim 1$.7-fold higher in visceral vs subcutaneous adipose tissue, both in men and women (Fig. 1a,b). There was no age-dependent effect on FASN gene expression (Table 2). To investigate whether these differences in expression can be explained by differences in body fat mass or fat distribution, we performed additional analyses in subgroups of lean $\left(\mathrm{BMI}<25 \mathrm{~kg} / \mathrm{m}^{2}\right.$ ) and obese $\left(B M I>30 \mathrm{~kg} / \mathrm{m}^{2}\right)$ participants with normal 
Table 2 Multivariate linear regression analyses showing the association of FASN mRNA expression in visceral subcutaneous fat with age and anthropometric and metabolic parameters for the entire study population $(n=198)$

\begin{tabular}{|c|c|c|}
\hline & $\begin{array}{l}\text { Visceral FASN } \\
\text { mRNA } \\
\beta \text {-Coefficient } \\
(p \text { value) }\end{array}$ & $\begin{array}{l}\text { Subcutaneous } \\
\text { FASN mRNA } \\
\beta \text {-Coefficient } \\
\text { ( } p \text { value) }\end{array}$ \\
\hline \multicolumn{3}{|l|}{ Model 1} \\
\hline Age (years) & $0.13(0.16)$ & $0.02(0.7)$ \\
\hline Sex & $-0.09(0.31)$ & $-0.022(0.7)$ \\
\hline \multicolumn{3}{|l|}{ Model 2} \\
\hline Age (years) & $-0.01(0.88)$ & $0.08(0.39)$ \\
\hline Sex & $-0.09(0.27)$ & $-0.08(0.4)$ \\
\hline Body fat (\%) & $0.53(<0.0001)^{\mathrm{a}}$ & $0.29(0.01)^{\mathrm{a}}$ \\
\hline \multicolumn{3}{|l|}{ Model 3} \\
\hline Age (years) & $-0.017(0.82)$ & $0.076(0.36)$ \\
\hline Sex & $-0.086(0.25)$ & $-0.088(0.29)$ \\
\hline $\begin{array}{l}\text { Visceral fat area } \\
\left(\mathrm{cm}^{2}\right)\end{array}$ & $0.47(0.0001)^{\mathrm{a}}$ & $0.2(0.02)^{\mathrm{a}}$ \\
\hline \multicolumn{3}{|l|}{ Model 4} \\
\hline Age (years) & $-0.06(0.4)$ & $0.006(0.9)$ \\
\hline Sex & $-0.15(0.075)$ & $-0.1(0.22)$ \\
\hline $\begin{array}{l}\text { Visceral fat area } \\
\left(\mathrm{cm}^{2}\right)\end{array}$ & $0.35(0.001)$ & $0.1(0.21)$ \\
\hline $\begin{array}{l}\text { GIR } \\
\quad\left(\mathrm{mg} \mathrm{kg}^{-1} \min ^{-1}\right)\end{array}$ & $-0.24(0.02)^{\mathrm{a}}$ & $-0.28(0.002)^{2}$ \\
\hline
\end{tabular}

${ }^{\mathrm{a}}$ Significant coefficients

GIR glucose infusion rate during the steady state of the euglycaemichyperinsulinaemic clamp

glucose tolerance. Based on CT scan measurement (L4-L5) of abdominal visceral and subcutaneous fat areas, obese subjects were further categorised as having predominantly visceral or subcutaneous obesity. Predominantly visceral obesity was defined as a ratio of visceral:subcutaneous fat area of $>0.5$, as previously described [22]. FASN mRNA levels were confirmed to be $\sim 1.7$-fold higher in visceral vs subcutaneous adipose tissue of all subgroups (Fig. 1c), and this increase was independent of differences in obesity and fat distribution. Visceral FASN mRNA expression was 2.1fold higher and subcutaneous FASN mRNA expression was 2.4-fold higher in obese vs lean individuals (Fig. 1c). We went on to investigate whether impaired glucose metabolism in patients with either IGT type 2 diabetes is associated with altered FASN expression in different fat depots. Subgroup analyses demonstrated that IGT and type 2 diabetic patients were indistinguishable with regard to FASN mRNA measurements, and therefore these groups were studied together. Patients with IGT/type 2 diabetes had significantly higher FASN expression, both in visceral and subcutaneous fat, compared with individuals with NGT (Fig. 1d). FASN expression was $\sim 1.4$-fold higher in visceral vs subcutaneous fat in IGT/type 2 diabetic patients. In a representative subgroup of lean $(n=10)$, predominantly viscerally obese $(n=10)$ and predominantly subcutaneously obese $(n=10)$ participants, we measured visceral and subcutaneous FASN protein levels (Fig. 1e). In parallel with the relatively higher levels of visceral vs subcutaneous FASN mRNA expression, visceral FASN protein levels were significantly increased in all subgroups (Fig. 1e). There were significant correlations between FASN mRNA and protein levels in subcutaneous $\left(R^{2}=0.44, p<0.001\right)$ and visceral fat depots $\left(R^{2}=0.5, p<0.001\right.$; Fig. 1f). In addition, there was a significant correlation between visceral and subcutaneous FASN mRNA expression across the entire study cohort $\left(R^{2}=0.5, p<0.001\right.$; Fig. $\left.2 \mathrm{a}\right)$, as well as in each of the subgroups (data not shown).

Correlation of FASN mRNA expression with parameters of obesity, glucose metabolism, and insulin sensitivity In the entire cohort $(n=198)$, univariate regression analysis revealed significant positive correlations between visceral and subcutaneous FASN mRNA expression and BMI, percentage body fat, visceral and subcutaneous fat area, WHR, fasting plasma insulin, $\mathrm{HbA}_{1 \mathrm{c}}$, NEFA, leptin, IL-6 and RBP4. There was an inverse correlation between visceral $F A S N$ mRNA expression and glucose uptake during the steady state of the euglycaemic-hyperinsulinaemic clamp. The correlation between visceral FASN mRNA expression and BMI $\left(R^{2}=0.24, p<0.0001\right)$, visceral fat area $\left(R^{2}=0.22\right.$, $p<0.001$; Fig. 2b), glucose infusion rate during the steady state of an euglycaemic-hyperinsulinaemic clamp $\left(R^{2}=0.2\right.$, $p<0.01$; Fig. $2 \mathrm{c})$, fasting plasma insulin concentrations $\left(R^{2}=\right.$ $0.13, p=0.03$; Fig. 2d), IL-6 $\left(R^{2}=0.2, p<0.0001\right)$, and RBP4 $\left(R^{2}=0.2, p<0.01\right.$; Fig. 3a) remained significant even upon adjusting for age, sex and percentage body fat. Interestingly, there were no significant correlations between subcutaneous FASN gene expression and anthropometric and metabolic parameters beyond those with age, sex and percentage body fat. Multivariate linear regression analysis revealed percentage body fat, visceral fat area and glucose infusion rate during clamp as significant predictors of visceral FASN mRNA expression, whereas only glucose infusion rate was a significant predictor of subcutaneous FASN mRNA expression (Table 2).

Of the adipokines, IL-6 was found to be the best predictor of visceral FASN mRNA expression (Table 3). Further analysis of other serum markers of obesity and/or insulin resistance showed that leptin and RBP4 serum concentrations are significant predictors of visceral FASN mRNA expression, and these associations were independent of age, sex and percentage body fat (Table 3).

Higher visceral FASN mRNA expression is related to increased markers of renal dysfunction Increased FASN expression was reported in experimental chronic renal failure in animal models [23]. We therefore investigated 
Fig. 2 Correlations between visceral (vis) FASN mRNA expression and a subcutaneous (SC) FASN mRNA expression $\left(R^{2}=0.5, p<0.001\right)$, b intraabdominal fat area (IAFA) $\left(R^{2}=\right.$ $0.22, p<0.001)$, c glucose uptake during the steady state of an euglycaemic-hyperinsulinaemic clamp and $\left(R^{2}=0.2, p<0.01\right) \mathbf{d}$ fasting plasma insulin concentration $\left(R^{2}=0.13, p=0.03\right)$. Data are log transformed to achieve normal distribution

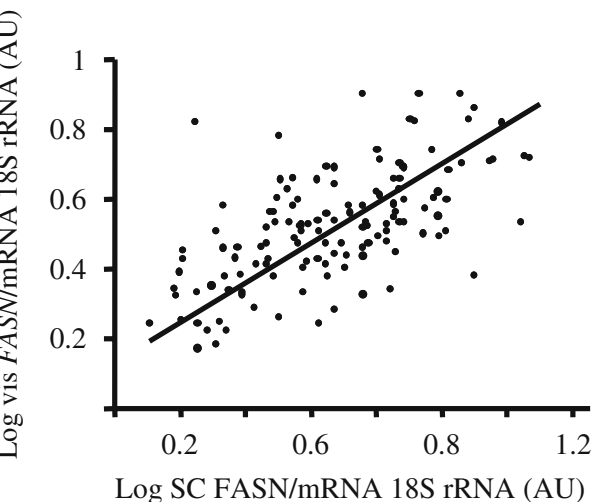

b

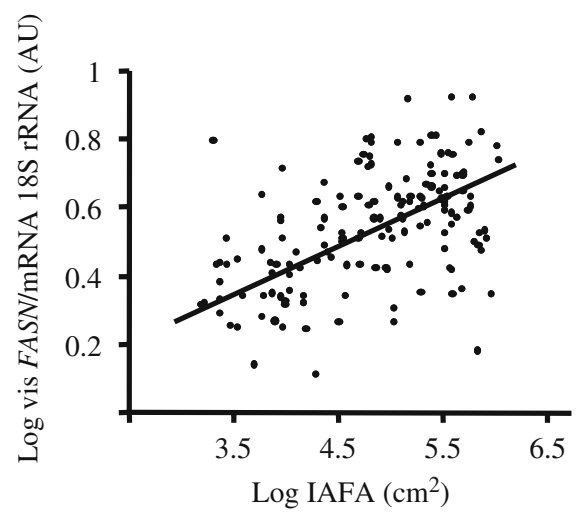

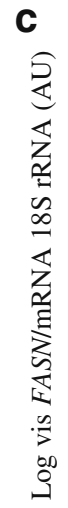

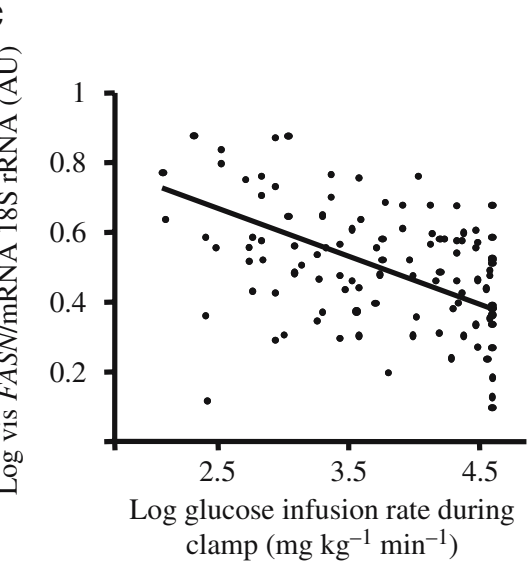

d

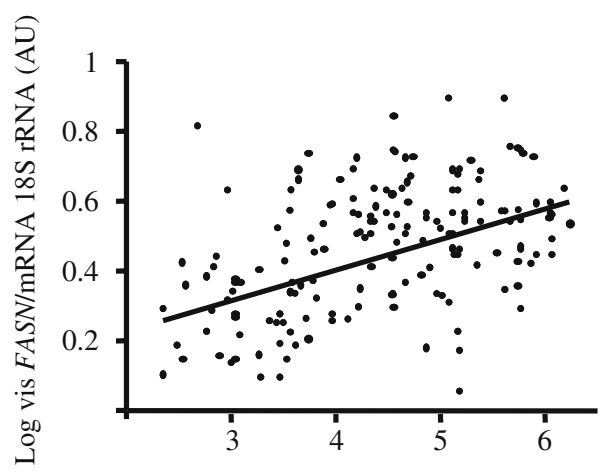

Log fasting plasma insulin $(\mathrm{pmol} / \mathrm{ml})$ the relationships of FASN mRNA expression in obese subjects and patients with IGT/type 2 diabetes with parameters of renal function. We found a significant correlation between visceral FASN expression and serum creatinine concentrations $\left(R^{2}=0.26, p=0.005\right.$; Fig. $\left.3 \mathrm{~b}\right)$, independent of age, sex and percentage body fat. However, adjusting for serum creatinine in multivariate regression analyses did not change significant relationships between FASN expression and percentage body fat, visceral fat area, glucose infusion rate during the steady state of the euglycaemic-hyperinsulinaemic clamp, fasting plasma in- sulin and IL-6 concentrations. Moreover, in IGT/type 2 diabetic patients, urinary albumin excretion was correlated with visceral FASN mRNA expression $\left(R^{2}=0.15, p=0.03\right)$, even after adjusting for age, sex and percentage body fat.

\section{Discussion}

FASN is the central enzyme in de novo lipogenesis, catalysing the conversion of malonyl CoA into palmitate
Fig. 3 Correlation of FASN mRNA expression with a RBP4 $\left(R^{2}=0.2, p<0.01\right)$ and $\mathbf{b}$ creatinine serum concentrations $\left(R^{2}=0.26, p=0.005\right)$. Data are $\log$ transformed to achieve normal distribution a

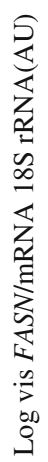

b

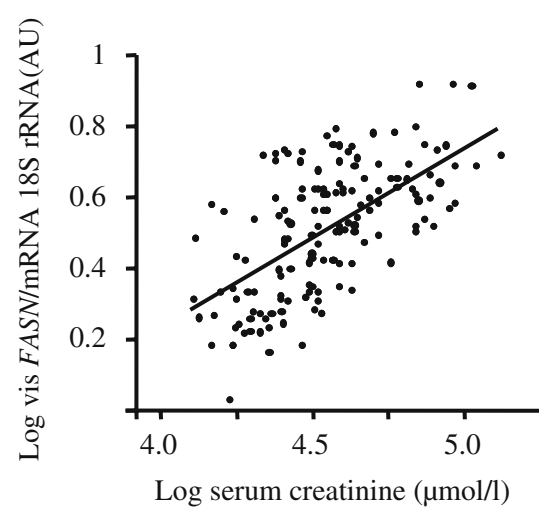


Table 3 Multivariate linear regression analysis of adipokines and parameters of dyslipidaemia as predictors of visceral $F A S N$ mRNA expression adjusted for age, sex and percentage body fat $(n=196)$

\begin{tabular}{|c|c|c|c|c|}
\hline \multirow[t]{2}{*}{ Parameter } & \multicolumn{2}{|c|}{ Visceral FASN mRNA } & \multicolumn{2}{|c|}{$\begin{array}{l}\text { Subcutaneous FASN } \\
\text { mRNA }\end{array}$} \\
\hline & $\begin{array}{l}\beta- \\
\text { Coefficient }\end{array}$ & $p$ value & $\begin{array}{l}\beta- \\
\text { Coefficient }\end{array}$ & $p$ value \\
\hline IL-6 & 0.36 & $<0.001$ & 0.3 & 0.005 \\
\hline Leptin & 0.28 & 0.008 & 0.24 & 0.009 \\
\hline RBP4 & 0.26 & 0.005 & 0.1 & 0.09 \\
\hline NEFA & 0.14 & 0.06 & 0.09 & 0.1 \\
\hline Triacylglycerol & 0.02 & 0.7 & 0.01 & 0.7 \\
\hline Adiponectin & -0.01 & 0.8 & -0.1 & 0.08 \\
\hline
\end{tabular}

$[8,9]$. In a recent study it was demonstrated that insulin, both alone and in combination with dexamethasone, increased human FASN gene expression and concomitantly elevated FASN activity [24]. Although the contribution of human adipose tissue to whole-body lipogenesis is considered to be low and less than that of liver $[6,7]$, adipose tissue remains an important site of endogenous fatty acid synthesis [25]. Expression of the FASN gene is primarily regulated by hormonal and nutritional signals [26]. FASN activity measurements and FASN mRNA levels are frequently used as markers of de novo lipogenesis, and changes in FASN activity are primarily due to alterations in the transcription rate of the $F A S N$ gene $[10,24,27]$. It was demonstrated in both murine cell lines and primary human adipocytes that insulin and angiotensin II increase the rate of FASN gene transcription $[10,27]$. In the present study we demonstrate that both visceral and subcutaneous FASN mRNA expression are closely correlated with FASN protein levels in both depots.

The important role of $F A S N$ as a candidate gene for the development of obesity was demonstrated in interventional $[1,2,14]$ and genetic studies [3, 16, 17]. Inhibition of FASN in rodents causes reduced food intake and profound weight loss $[1,2]$. It is noteworthy that adipose tissue lipogenic capacity and FASN expression and FASN production are lower in humans vs rodents [6], and therefore it still needs to be clarified whether the results of rodent studies are applicable for the human regulation of adipose lipogenesis. However, a missense substitution in the FASN gene was found to be associated with percentage body fat in non-diabetic Pima Indians [3].

Consequences of excess energy intake include hyperinsulinaemia, elevated triacylglycerol and NEFA serum concentrations, increased or decreased circulating adipokines and others. These outcomes could potentially lead to higher FASN expression and FASN activity, resulting in increased lipogenesis. Thus, we hypothesised that FASN expression plays a role in the causal relationship between the metabolic consequences of excess energy intake and increased fat mass. We therefore investigated in vivo whether increased FASN gene expression in human adipose tissue contributes to the development of obesity. We also aimed to determine which metabolic abnormalities are significantly related to $F A S N$ mRNA expression in adipose tissue. FASN gene expression was studied in adipose tissue using quantitative real-time RT-PCR in paired samples of visceral and subcutaneous adipose tissue from 196 volunteers who varied widely in terms of obesity, body fat distribution and metabolic parameters. We used correlational analysis to dissect whether and to what extent FASN mRNA expression is explained by the variability in anthropometric and metabolic parameters. FASN mRNA expression was significantly higher in visceral vs subcutaneous adipose tissue, independent of BMI or body fat distribution. This finding is in accordance with high FASN expression in intra-abdominal adipose tissue [18]. Although there was a correlation between visceral and subcutaneous FASN mRNA expression, the fact that visceral FASN expression was in general higher than subcutaneous expression suggests that FASN predominantly mediates the adverse effects of obesity and excess energy intake in visceral fat. $F A S N$ gene expression is significantly higher in obese vs lean individuals, supporting our previous results that FASN expression and FASN levels correlate with adipocyte size $[11,12]$. In contrast to our results, Diraison et al. [4] found that FASN mRNA expression was decreased in the subcutaneous adipose tissue of obese vs lean individuals [4]. Differences in nutritional status, metabolic parameters and the size of the study population (the previous study [4] was of much smaller size) might explain these divergent findings.

The results of the present study also demonstrate that adipose $F A S N$ gene expression is higher in patients with type 2 diabetes or IGT vs individuals with NGT. Independently of age, sex and body fat mass, increased FASN expression was shown to be primarily related to impaired insulin sensitivity, whereas no correlation was found between FASN expression and acute or chronic hyperglycaemia, which goes beyond the relationships with BMI or percentage body fat. Since $F A S N$ gene expression is increased by insulin stimulation [10], elevated plasma insulin concentrations in insulin-resistant states could represent a potential mechanism for the increased $F A S N$ expression in the adipose tissue of obese and insulinresistant subjects. As previously shown in mice with an adipose tissue-specific deletion of the insulin receptor, impaired insulin sensitivity in fat does not lead to decreased FASN protein production in large adipocytes [11].

Our study design also allowed us to investigate the relationships between FASN mRNA expression and serum concentrations of different adipokines and circulating 
markers of insulin resistance. In multivariate linear regression analyses we found that circulating levels of IL-6 predict visceral $F A S N$ expression, independently of age, sex and percentage body fat. Visceral FASN gene expression was also found to be related to serum concentrations of RBP4 and leptin. Leptin could directly induce FASN mRNA expression in adipose tissue, since adipocyteselective reduction of the leptin receptor in mice has been observed to decrease FASN mRNA expression [28]. However, experimentally increased plasma leptin concentrations in rats resulted in a decrease of FASN mRNA levels in fat [29]. Notably, in chickens, leptin was shown to increase FASN gene expression in the liver [30]. Therefore, we cannot exclude the possibility that increased serum concentrations of leptin in obese subjects contribute to increased FASN mRNA expression in fat. Circulating levels of RBP4 were identified as another significant predictor of FASN mRNA expression. Since RBP4 is closely associated with obesity and insulin resistance [19, 31], further studies are required to elucidate a potential direct role of RBP4 in stimulating $F A S N$ gene expression. Multivariate regression analysis also identified a significant association of visceral FASN expression and creatinine serum concentrations. Moreover, in patients with type 2 diabetes/IGT, we found a significant correlation between microalbuminuria and adipose tissue FASN mRNA expression. These results confirm previous studies in rodents, showing that FASN gene expression is upregulated in experimental chronic renal failure [23, 32]. However, patients with renal dysfunction were excluded from our study. Notably, adjusting for either serum creatinine or microalbuminuria had no effect on significant relationships between FASN expression, percentage body fat, visceral fat area and parameters of insulin resistance. Therefore, FASN expression appears to be independently related to renal function, but elucidation of the exact mechanisms will require more sophisticated methods and study designs.

In conclusion, although it is not possible to establish a true causability chain, our data are compatible with the notion that increased FASN expression in adipose tissue links excess energy intake and accumulation of body fat. Thereby, adipose FASN mRNA expression is significantly related to obesity, predominantly visceral fat accumulation, impaired insulin sensitivity and circulating adipokines. Moreover, in addition to chronic hyperinsulinaemia, elevated leptin and RBP4 serum concentrations in obesity might contribute to increased FASN expression. Thus, inhibition of FASN specifically in adipose tissue may be a promising therapeutic approach in the prevention and treatment of obesity and its complications.

Acknowledgements This work was supported by grants from Deutsche Forschungsgemeinschaft (DFG; German Research Founda- tion) BL 580/3-1 (to M. Blüher), the Clinical Research group 'Atherobesity' KFO 152 (project BL 833/1-1) (to M. Blüher) and the Interdisciplinary Center of Clinical Research (IZKF) Leipzig at the Faculty of Medicine of the University of Leipzig (Project N03 to J. Berndt and P. Kovacs, and project B24 to M. Blüher).

Duality of interest The authors declare that there was no duality of interest associated with this study.

\section{References}

1. Mobbs CV, Makimura H (2002) Block the FAS, lose the fat. Nat Med 8:335-336

2. Loftus TM, Jaworsky DE, Frehywot GL et al (2000) Reduced food intake and body weight in mice treated with fatty acid synthase inhibitors. Science 288:2379-2381

3. Kovacs P, Harper I, Hanson RL et al (2004) A novel missense substitution (Val1483Ile) in the fatty acid synthase gene (FAS) is associated with percentage of body fat and substrate oxidation rates in nondiabetic Pima Indians. Diabetes 53:1915-1919

4. Diraison F, Dusserre E, Vidal H, Sothier M, Beylot M (2002) Increased hepatic lipogenesis but decreased expression of lipogenic gene in adipose tissue in human obesity. Am J Physiol Endocrinol Metab 282:46-51

5. Aarsland A, Chinkes D, Wolfe RR (1996) Contributions of de novo synthesis of fatty acids to total VLDL-triglyceride secretion during prolonged hyperglycemia/hyperinsulinemia in normal man. J Clin Invest 98:2008-2017

6. Letexier D, Pinteur C, Large V, Frering V, Beylot M (2003) Comparison of the expression and activity of the lipogenic pathway in human and rat adipose tissue. J Lipid Res 44:21272134

7. Marin P, Hogh-Kristiansen I, Jansson S, Krotkiewski M, Holm G, Bjorntorp P (1992) Uptake of glucose carbon in muscle glycogen and adipose tissue triglycerides in vivo in humans. Am J Physiol 263:E473-E480

8. Hillgartner FB, Salati LM, Goodridge AG (1995) Physiological and molecular mechanisms involved in nutritional regulation of fatty acid synthesis. Physiol Rev 75:47-76

9. Semenkovich CF (1997) Regulation of fatty acid synthase (FAS). Prog Lipid Res 36:43-53

10. Claycombe K, Jones B, Standridge M et al (1998) Insulin increases fatty acid synthase gene transcription in human adipocytes. Am J Physiol Regul Integr Comp Physiol 274: R1253-R1259

11. Blüher M, Michael MD, Peroni OD et al (2002) Adipose tissue selective insulin receptor knockout protects against obesity and obesity-related glucose intolerance. Dev Cell 3:25-38

12. Blüher M, Patti ME, Gesta S, Kahn BB, Kahn CR (2004) Intrinsic heterogeneity in adipose tissue of fat-specific insulin receptor knock-out mice is associated with differences in patterns of gene expression. J Biol Chem 279:31891-31901

13. Shimokawa T, Kumar MV, Lane MD (2002) Effect of a fatty acid synthase inhibitor on food intake and expression of hypothalamic neuropeptides. Proc Natl Acad Sci USA 99:66-71

14. Kumar MV, Shimokawa T, Nagy TR, Lane MD (2002) Differential effects of a centrally acting fatty acid synthase inhibitor in lean and obese mice. Proc Natl Acad Sci USA 99: 1921-1925

15. Dridi S, Ververken C, Hillgartner FB et al (2006) FAS inhibitor cerulenin reduces food intake and melanocortin receptor gene 
expression without modulating the other (an)orexigenic neuropeptides in chickens. Am J Physiol Regul Integr Comp Physiol 291:138-147

16. Sourdioux M, Brevelet C, Delabrosse Y, Douaire M (1999) Association of fatty acid synthase gene and malic enzyme gene polymorphisms with fatness in turkeys. Poult Sci 78:1651-1657

17. Körner A, Ma L, Franks PW et al (2007) Sex-specific effect of the Val1483Ile polymorphism in the fatty acid synthase gene (FAS) on body mass index and lipid profile in Caucasian children. Int J Obes (Lond) 31:353-358

18. Semenkovich CF, Coleman T, Fiedorek FT Jr (1995) Human fatty acid synthase mRNA: tissue distribution, genetic mapping, and kinetics of decay after glucose deprivation. J Lipid Res 36:15071521

19. Graham TE, Yang Q, Blüher M et al (2006) Retinol binding protein-4 (RBP-4) and insulin resistance in lean, obese, and type 2 diabetic subjects. N Engl J Med 354:2552-2563

20. DeFronzo RA, Tobin JD, Andres R (1979) Glucose clamp technique: a method for quantifying insulin secretion and resistance. Am J Physiol 237:214-223

21. Blüher M, Unger R, Rassoul F, Richter V, Paschke R (2002) Relation between glycaemic control, hyperinsulinaemia and plasma concentrations of soluble adhesion molecules in patients with impaired glucose tolerance or type II diabetes. Diabetologia 45:210-216

22. Berndt J, Klöting N, Kralisch S et al (2005) Plasma visfatin concentrations and fat depot-specific mRNA expression in humans. Diabetes 54:2911-2916

23. Szolkiewicz M, Nieweglowski T, Korczynska J et al (2002) Upregulation of fatty acid synthase gene expression in experimental chronic renal failure. Metabolism 51:1605-1610
24. Wang Y, Jones Voy B, Urs S et al (2004) The human fatty acid synthase gene and de novo lipogenesis are coordinately regulated in human adipose tissue. J Nutr 134:1032-1038

25. Swierczynski J, Goyke E, Wach L et al (2000) Comparative study of the lipogenic potential of human and rat adipose tissue. Metabolism 49:594-599

26. Sul HS, Wang D (1998) Nutritional and hormonal regulation of enzymes in fat synthesis: studies of fatty acid synthase and mitochondrial glycerol-3-phosphate acyltransferase gene transcription. Annu Rev Nutr 18:331-351

27. Jones BH, Standridge MK, Moustaid N (1997) Angiotensin II increases lipogenesis in 3T3-L1 and human adipose cells. Endocrinology 138:1512-1519

28. Huan JN, Li J, Han Y, Chen K, Wu N, Zhao AZ (2003) Adipocyte-selective reduction of the leptin receptors induced by antisense RNA leads to increased adiposity, dyslipidemia, and insulin resistance. J Biol Chem 278:45638-45650

29. Nogalska A, Sucajtys-Szulc E, Swierczynski J (2005) Leptin decreases lipogenic enzyme gene expression through modification of SREBP-1c gene expression in white adipose tissue of aging rats. Metabolism 54:1041-1047

30. Dridi S, Buyse J, Decuypere E, Taouis M (2005) Potential role of leptin in increase of fatty acid synthase gene expression in chicken liver. Domest Anim Endocrinol 29:646-660

31. Yang Q, Graham TE, Mody N et al (2005) Serum retinol binding protein 4 contributes to insulin resistance in obesity and type 2 diabetes. Nature 436:356-362

32. Korczynska J, Stelmanska E, Nogalska A et al (2004) Upregulation of lipogenic enzymes genes expression in white adipose tissue of rats with chronic renal failure is associated with higher level of sterol regulatory element binding protein-1. Metabolism 53:1060-1065 